\title{
Women Gastroenterologists in Academic Medicine: Tradition Versus Transition
}

\author{
Rocio Feliu-Dominguez ${ }^{1} \cdot$ Priscilla Medero-Rodriguez $^{1} \cdot$ Marcia Cruz-Correa $^{1,2,3,4,5}$
}

Published online: 10 November 2016

(c) Springer Science+Business Media New York 2016

Most women experience childhood dreams of being a grownup, with a pretty house with a white picket fence and children running around. That same little girl wanted to be a doctor; she grew up and had to face the reality that life is more complex than her dreams and that being a female gastroenterologist in this era is a multifaceted endeavor. Gastroenterology as a specialty offers the opportunity to provide long-term care to our patients and enjoy the technical aspects of endoscopy and other procedures. Until as recently as 1990, fewer than 5\% of gastroenterologists were women, possibly due to the perception at the time that the practice of gastroenterology was associated with long and irregular hours, frequent night call, harsh physical strength, and quite frankly, working with aesthetically challenging bodily emanations. Recently, when more women started to consider gastroenterology as a subspecialty, there was also increased interest by women in technology, a gender shift that may reflect changes in women's places in society. Nevertheless, since gastroenterology remains a physically and intellectually demanding

Marcia Cruz-Correa

marcia.cruz1@upr.edu

1 Department of Medicine, University of Puerto Rico School of Medicine, San Juan, PR, USA

2 Department of Biochemistry, University of Puerto Rico School of Medicine, San Juan, PR, USA

3 Department of Surgery, University of Puerto Rico School of Medicine, San Juan, PR, USA

4 University of Puerto Rico Comprehensive Cancer Center, PMB 711, De Diego Avenue 89 Suite 105, San Juan, PR 00927-6346, USA

5 Division of Gastroenterology, Johns Hopkins School of Medicine, Baltimore, MD, USA subspecialty, conflicts between personal and career goals arise as women transition from fellowship to practice. It is expected that as women struggle to balance family and career, the discovery of new approaches to traditional women's contributions toward academic gastroenterology and career pathways is warranted.

\section{Balancing Family and Career}

Balancing family with personal life in the context of a gastroenterology career has become a very "hot" topic for women, in part because of the influx of women into the specialty and because gastroenterology is a procedurebased career requiring longer working hours, in hospital service and after hour duties. When we planed a career in medicine, we were focused in the professional aspects of it. The personal statements included in our medical school applications probably did not include being a mom, a spouse, and getting home early as our top priorities. But as we get older, marriage, children, and family enter the picture and suddenly we want it all. But, can we have it all? Can we have that academic gastroenterologist position and that perfect family? Our inner superwoman quickly answers "yes!" But, is it realistic? Are we fooling ourselves? Is this the road to happiness?

There has been an increasing trend among female physicians, more so in gastroenterology, to delay motherhood to pursue educational and career goals, which as a consequence has increased the rate of involuntary childlessness [1], including the avoidance of pregnancy to pursue training in certain endoscopic procedures. For example, those women in gastroenterology who perform procedures that include fluoroscopy are more prone to avoid pregnancy to avoid the unknown risks to the fetus. When we dreamt 
about the "house full of children," we failed to consider the rigors and risks inherent in pursuing a career that included attending medical school and completing internal medicine residency, postgraduate training, and gastroenterology fellowship. We also failed to take into account that professional women in many families remain responsible for the majority of domestic and child-related duties [2]. Furthermore, medical institutions remain oriented toward traditional families of the past, rather than today's dual-career family or single parent [2]. Alternative models including job-sharing or creative scheduling are not commonly offered at most organizations. Similarly, on-site daycare for trainees and staff is very uncommon at most academic centers.

\section{Gender Responsibilities and Academic Gastroenterology}

There is still a societal dichotomy in gender-based expectations for men and women. Even when almost $50 \%$ of medical students are women, only $13 \%$ of practicing gastroenterologists are females [3]. Of note, women constitute $36 \%$ of gastroenterology fellows [4] according to recent data from the American Gastroenterological Association (AGA). This slower increase in the number of female gastroenterologists could be explained by women's awareness of their "expected societal roles" (mother, daughter, partner, daughter-in-law) and the demands of gastroenterology as a subspecialty with less predictive hours, inpatient services, and endoscopy services. For some female physicians, family demands require shifting professional priorities [5] which also includes their choices in specialties and subspecialties. Women are more likely to alter their careers, job responsibilities, and work hours to benefit their families [6]. According to a survey evaluating gender differences among married physicians with children, $85 \%$ of female physicians made career changes for the benefit of their children and family, whereas only $35 \%$ of male physicians made similar adjustments; the most common alteration being a reduction in work hours. Another survey found that women worked part-time to combine their careers with childbearing, whereas men did so to combine their faculty position with private practice [7].

These differences in gender-based responsibilities, assumptions, and expectations have created stress and strains among female physicians. A 2009 study by the University of Minnesota Medical School reported that although male and female faculties were equally productive and worked the same amount of hours, women spent 12 more hours per week in family and household responsibilities compared to men despite spending the same number of hours at work. Women were also less likely than men to have partners or spouses (19 vs. 5\%). Seventy percent of women had partners who were employed fulltime versus $36 \%$ of men. As women were less likely than men to have partners and are more likely to have employed partners, women were less likely to have help with family and household responsibilities [8]. For a subspecialty as gastroenterology, these trends have been not formally examined. Understanding the specific career-family issues within our specialty merits examination to help guide programs and pathways that will promote retention of women in academic gastroenterology.

Women are more prone to leave academic gastroenterology and less likely to achieve the rank of professor, even when more females than males enter academic medicine [9]. Frustration with productivity, career advancement, as well as balancing the gastroenterology career and family responsibilities may contribute to a female faculty member's decision to leave a faculty position [1]. This dissatisfaction of the female physician has become an important economic problem for academic medical centers since replacing a faculty member could cost an institution $\$ 115,000-\$ 400,000$ [10].

\section{Summary}

There is no single answer for the women gastroenterologist on how to "do it all." Considering part-time work, performing less procedures, reducing travel time, working close to home, taking family leave, taking summers off, and involving extended family in childcare could ease our journey [2]. Changes in the working environment such as extended maternity leave arrangements, childcare within the institution with flexible hours, or different tracks for promotion may be reasonable alternatives to attract and retain women in academic medicine.

Nonetheless, there are many women in gastroenterology that have been able to have successful academic careers as scientists, educators, and clinicians while maintaining a satisfying personal life. Advancement to leadership positions within gastroenterology professional organizations (AGA, AASLD, ACG, ASGE) has been increasing as demonstrated by the growth in the number of female gastroenterologists reaching leadership positions, including Presidency, which was quite uncommon historically.

There is not a one-size-fits-all model for thriving in academic medicine while thriving as a mother/partner/daughter or any other personal obligations one may have. Yet, the key remains in understanding our priorities and being proactive about our needs to thrive professionally while remaining authentic to our personal goals. Since over a third of the gastroenterology fellows are women, [4] 
revision of curricula, promotion tracks, and working hours will be integral to support the growing number of talented women that are vital to the continuous progress of our profession. Hence, establishing task forces to examine best practices for women in academic gastroenterology is a clear next step. Gastroenterology professional organizations are well positioned to lead the way into this transformation of our profession.

Being a female physician in academic gastroenterology is full of satisfactions, but it also has its challenges. Can we "do it all" and "have it all"? Probably not, but we can do and have many things. Most importantly we can have what is important to us. We need to regularly assess our priorities and understand that life is full of unexpected turns. We can learn to say "no." Balancing family with career takes energy, flexibility, and learning to deal with unpredictability. It requires patience with one's own limits and imperfections [2,11-19]. At the end it is all worth it; we can thrive as women in academic gastroenterology and have a fulfilling life.

\section{References}

1. Beckett L, et al. Do family responsibilities and a clinical versus research faculty position affect satisfaction with career and worklife balance for medical school faculty? J Womens Health (Larchmt). 2015;24:471-480.

2. Verlander G. Female physicians: balancing career and family. Acad Psychiatry. 2004;28:331-336.

3. Pallardy C. Male \& female active physicians: 70 statistics by specialty. Becker's GI \& Endoscopy, 2015. http://www.beck ersasc.com/gastroenterology-and-endoscopy/male-female-activephysicians-70-statistics-by-specialty.html.

4. Shukla R. Current challenges facing women in gastroenterology: how do we move forward? ACG Case Reports Journal. 2016;3:144-145.
5. Smith MJ. Women in gastroenterology struggle to find work-life balance. Gastroenterol Endoscopy News. 2010;61:1-5.

6. Warde C, Allen W, Gelberg L. Physician role conflict and resulting career changes. Gender and generational differences. $J$ Gen Intern Med. 1996;11:729-735.

7. Levinson W, Kaufman K, Bickel J. Part-time faculty in academic medicine: present status and future challenges. Ann Intern Med. 1993;119:220-225.

8. Shollen SL, et al. Organizational climate and family life: how these factors affect the status of women faculty at one medical school. Acad Med. 2009;84:87-94.

9. Nonnemaker L. Women physicians in academic medicine: new insights from cohort studies. N Engl J Med. 2000;342:399-405.

10. Waldman JD, et al. The shocking cost of turnover in health care. Health Care Manage Rev. 2004;29:2-7.

11. Dyrbye LN, et al. Physicians married or partnered to physicians: a comparative study in the American College of Surgeons. J Am Coll Surg. 2010;211:663-671.

12. Myers MF. Medical marriages and other intimate relationships. Med J Aust. 2004;181:392-394.

13. Carnes M, et al. Why is John more likely to become department chair than Jennifer? Trans Am Clin Climatol Assoc. 2015;126: 197-214.

14. Jerg-Bretzke L, Limbrecht K. Where have they gone? A discussion on the balancing act of female doctors between work and family. GMS Z Med Ausbild 2012; 29: Doc19.

15. Hawker FH. Female specialists in intensive care medicine: job satisfaction, challenges and work-life balance. Crit Care Resusc. 2016;18:131.

16. Stephens EH, et al. Gender and cardiothoracic surgery training: specialty interests, satisfaction, and career pathways. Ann Thorac Surg. 2016;102:200-206.

17. Diamond SJ, et al. Gender differences in publication productivity, academic rank, and career duration among U.S. Academic Gastroenterology Faculty. Acad Med. 2016;91:1158-1163.

18. Edmunds LD, et al. Why do women choose or reject careers in academic medicine? A narrative review of empirical evidence. Lancet. 2016. doi:10.1016/S0140-6736(15)01091-0.

19. Boydstun J, Cossman JS. Career expectancy of physicians active in patient care: evidence from Mississippi. Rural Remote Health. 2016;16:3813. 